\title{
M. Joqueviel-Bourjea, Jacques Réda. À pied d'œuvre
}

\section{Fabio Scotto}

\section{(Q) OpenEdition}

\section{Journals}

\section{Edizione digitale}

URL: http://journals.openedition.org/studifrancesi/10062

DOI: 10.4000/studifrancesi. 10062

ISSN: 2427-5856

\section{Editore}

Rosenberg \& Sellier

\section{Edizione cartacea}

Data di pubblicazione: 1 août 2017

Paginazione: $400-401$

ISSN: 0039-2944

\section{Notizia bibliografica digitale}

Fabio Scotto, «M. Joqueviel-Bourjea, Jacques Réda. À pied d"œuvre», Studi Francesi [Online], 182 (LXI I

II) | 2017, online dal 01 août 2017, consultato il 06 janvier 2021. URL: http://journals.openedition.org/ studifrancesi/10062 ; DOI: https://doi.org/10.4000/studifrancesi.10062

\section{Questo documento è stato generato automaticamente il 6 janvier 2021}

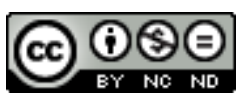

Studi Francesi è distribuita con Licenza Creative Commons Attribuzione - Non commerciale - Non opere derivate 4.0 Internazionale. 


\title{
M. Joqueviel-Bourjea, Jacques Réda. À pied d'œuvre
}

\author{
Fabio Scotto
}

\section{NOTIZIA}

MARIE JOQUEVIEL-BOURJEA, Jacques Réda. À pied d'œuvre, Paris, Honoré Champion, 2015, «Poétiques et esthétiques $\mathrm{xx}^{\mathrm{e}}$ et XxI ${ }^{\mathrm{e}}$ siècles» 21, $465 \mathrm{pp}$.

1 L'A. di questa ampia monografia, docente all'Université de Montpellier 3 e specialista di poesia moderna e contemporanea, ha già tra l'altro dedicato un volume a Jacques Réda, dal titolo Jacques Réda, la dépossession heureuse (Paris, L'Harmattan, 2006) e su Réda aveva anche incentrato la sua tesi di dottorato. Poeta prolifico difficilmente classificabile e a suo modo fantaisiste, Jacques Réda, da tempo consulente per la poesia delle edizioni Gallimard, è qui letto alla luce di una convinzione ben esplicitata nell'«Avant-propos» dal titolo «Les mots, la marche, la musique» (pp. 11-25), ovvero quella secondo la quale questi tre termini costituirebbero una «sainte trinité profane» che articolerebbe il discorso poetico come una fuga musicale (come è noto Réda s'interessa di jazz, specie di swing, e ne scrive su periodici specializzati), dove «l'en marche rimbaldien» prevarrebbe sulla "fflânerie" baudelairienne», per via di una scrittura che farebbe dell'incedere del «poète-marcheur» una danza fine a se stessa, da cui scaturirebbe un pensiero ritmico dell'Uno irriducibile a modelli contemporanei presenti.

2 Articolato in tre parti, per totali diciotto capitoli, lo studio di Joqueviel-Bourjea si propone, oltre che di sondare dalle varie angolazioni cui induce l'opera di Jacques Réda, anche di tentare di mettere in relazione quanto da quest'opera s'irradia in termini d'influssi e d'influenze al fine di ricostruire, per così dire, una geografia intellettuale legata al mondo delle letture e della critica che ne promana, ma anche una topografia urbana e mentale che si articola attorno a una singolare nozione di spazio.

3 La prima parte «Métamorphoses» esplora, da una prospettiva tesa a superare la distinzione fra verso e prosa nel suo lirismo, l'ambito poetico del lavoro di Réda, senza 
mai disdegnare incursioni nella narrativa e nella fiction che ne sono addentellati costitutivi e imprescindibili, anche allo scopo di osare individuarvi un pensiero, che, benché certo non di rilievo speculativo, comunque esamina campi d'indagine quali quello della presenza, della percezione del reale e dell'articolazione fra corpo che cammina e scrittura. La poesia è un costituirsi che nel contempo si dissolve e dice questa transizione dalla presenza all'assenza, anche attraverso il lutto e l'ironia che lo medica, ironia che tuttavia si concilia con il lirismo, tra adesione e distanziazione (qui l'A. si richiama alla nozione di «pacte lyrique» proposta da Antonio Rodriguez, che per l'appunto trova conciliabili lirismo e ironia, pp. 41-42). Da questo punto di vista, Joqueviel-Bourjea sostiene che «la poésie rédienne relève le défi d'une naïveté renouvellée par l'ironie» (p. 44).

Ironizzazione dell'io, sua ambivalenza ontologica sono esaminati lungo il corpus della produzione rédiana facendoli per contrasto interagire con la tematica tragica del lutto, vista nel confronto con alcune note opere di Michel Deguy, Jacques Roubaud e Claude Esteban (chapitre 3), mentre nel romanzo, cui il poeta parallelamente si dedica dal 2002 (ad esso sono dedicati i tre capitoli successivi della prima parte), sembra compiersi il passo decisivo dal verso alla prosa già prefigurato dalle prose poetiche precedenti, senza che però, fra diarismo breve e narrazione, mai si compia un mutamento di ricezione nel pubblico e nella critica, che continueranno a vedervi i testi in prosa di un poeta. La studiosa ben mostra come s'instauri una diversa temporalità, meno legata a schemi tradizionali quali risultavano spesso quelli delle poesie, tutte incentrate sull'amplificazione di un istante particolare colto come epifania nel suo antitetico portato d'effimero e d'eternità. Qui l'autobiografico, indica l'A., è sottoposto alla prova del romanzesco (p. 132), ne sono delineate le modalità stilistiche e operative, dalla finzionalizzazione dell'autobiografico ai meccanismi di descrizione e rappresentazione.

5 La seconda parte «Correspondances» allarga lo sguardo sul rapporto che Réda stabilisce con le proprie fonti, ovvero sul rapporto con l'esperienza della lettura (Verlaine, Claudel, Perros), intesa come «reconnaissante», ovvero come ri-conoscimento di sé attraverso la scrittura dell'altro e riconoscenza allo stesso per averci illuminato, e della scrittura critica conseguente. Ecco allora il discorso estendersi anche alla musica (il jazz) e alla pittura (Nicolas de Staël), nel solco della lezione simbolista, modo di cogliere il funzionamento odierno delle metonimie reciproche fra le arti, soggette a meccanismi di sostituzione, mimesi e oggettivazione della rappresentazione (si veda, nel solco di Derrida, la pluralità metaforica esemplare del «mur» alle pp. 312-313).

6 La terza parte «Topoïétiques» mutua il titolo dalle riflessioni contenute nel saggio del filosofo Michel Guérin L'espace plastique (Bruxelles, La Part de l'œil, 2008), le quali, pur se non perfettamente sovrapponibili al discorso poetico di Jacques Réda, comunque si prestano a una percezione non solo passiva, ma anche attiva dello spazio come «percevant» (p. 30); ne consegue in Réda una poetizzazione del luogo e, chiasticamente, una localizzazione della poesia che consente una dinamica appercezione del mondo attraverso il corpo («en-corps», p. 31) che supera ogni metaforizzazione uniformatrice e sedentarizzante dell'attività euristica. Poetica della città e della voce, in un singolare confronto fra Cendrars, Réda e Bonnefoy (pp. 319-341), presiedono a una heideggeriana abitazione poetica del mondo, con proiezioni verso l'universo topografico europeo, provinciale, urbano che prende progressivamente la forma di un «prosimètre moderne» il quale integra prosa e verso in un «devenir-roman» (pp. 431-432). 